\title{
3D Multiphysical Modelling of Fluid Dynamics and Mass Transfer in Laser Welding of Dissimilar Materials
}

\author{
Jiazhou Wu, Hua Zhang *, Yan Feng and Bingbing Luo
}

Key Laboratory of Robot and Welding Automation of Jiangxi, School of Mechanical and Electrical Engineering, Nanchang University, Nanchang 330031, China; woojz12@126.com (J.W.); fengyan76@ncu.edu.cn (Y.F.); lbingbing11@126.com (B.L.)

* Correspondence: huazhang_ncu@126.com; Tel.: +86-791-8396-9630

Received: 15 May 2018; Accepted: 6 June 2018; Published: 11 June 2018

\begin{abstract}
A three-dimensional multiphysical transient model was developed to investigate keyhole formation, weld pool dynamics, and mass transfer in laser welding of dissimilar materials. The coupling of heat transfer, fluid flow, keyhole free surface evolution, and solute diffusion between dissimilar metals was simulated. The adaptive heat source model was used to trace the change of keyhole shape, and the Rayleigh scattering of the laser beam was considered. The keyhole wall was calculated using the fluid volume equation, primarily considering the recoil pressure induced by metal evaporation, surface tension, and hydrostatic pressure. Fluid flow, diffusion, and keyhole formation were considered simultaneously in mass transport processes. Welding experiments of $304 \mathrm{~L}$ stainless steel and industrial pure titanium TA2 were performed to verify the simulation results. It is shown that spatters are shaped during the welding process. The thickness of the intermetallic reaction layer between the two metals and the diffusion of elements in the weld are calculated, which are important criteria for welding quality. The simulation results correspond well with the experimental results.
\end{abstract}

Keywords: laser welding; keyhole; weld pool behavior; mass transfer; dissimilar metal

\section{Introduction}

Dissimilar metal welding often confronts the problems of brittle intermetallic compounds, residuals stresses, and crack formations, which lead to lower joint performance. Thethickness of an intermetallic reaction layer is an important factor affecting the formation of intermetallic compounds, besides the differences in the physical and chemical properties of the materials. As long as the thickness of the intermetallic reaction layer is maintained in the proper range, the welded workpiece will have good mechanical properties. If the thickness is too large, it is possible for new intermetallic compounds to be formed, which makes the welded joint brittle and hard and reduces plasticity and ductility. Therefore, precise control of the heat source is highly important in the welding process. Compared with the traditional welding method, laser welding has several advantages such as precise energy control, high density due to minimal laser beam diameter, and narrow heat affected zones. The rapid melting and solidification of metal can reduce the formation of intermetallic compounds in laser welding of dissimilar materials, which improves the mechanical properties of the welded joint. Laser welding is an important joining method for dissimilar metals.

The behaviors of keyhole and weld pool have an important influence on welding quality in deep penetration laser welding, which has been widely confirmed through theoretical and experimental research. Early studies primarily focused on the analysis of temperature and heat flow fields in 
similar metal welding processes. Rai et al. [1,2] proposed a numerical model for keyhole mode laser welding to calculate the temperature and velocity fields, weld geometry, and solidification for different materials. Their results suggested that convection was the primary mechanism for heat transfer; however, the upper surface of the workpiece was assumed to be flat, and the shape of the keyhole was not the actual vapor-liquid interface, as this model did not consider the effect of the recoil pressure induced by metal evaporation. In recent years, research on keyhole formation, molten pool dynamics, and welding defects such as the formation of porosity and spatter has become a heavily researched topic. Na et al. [3,4] and Pang et al. [5-7] obtained the shape of a real-time keyhole, the model of which used a ray tracing method to simulate multiple laser reflections along the keyhole wall. Their study suggested that the formation of the keyhole was a result of the interaction of the recoil pressure caused by metal vaporization, the surface tension, and hydrostatic pressure. In addition, the formation of pores was due to the collapse of the keyhole. Recently, Hua et al. [8,9] performed a simulation study on the mechanism of spatter formation at full penetration condition. Their results suggested that the shear force generated by the high-speed plasma movement was the main cause of spatter formation, which was in full agreement with the experimental results of Chen et al. [10].

Although laser welding processes of the dissimilar metals and same metals are somewhat similar, laser welding of dissimilar materials has its own individual features, such as the formation of intermetallic compounds. Hu et al. [11] developed a 3D heat and mass transfer model of steel-nickel laser welding to analyze the influence of convection on the temperature field and mass transfer, and their results suggested that strong convection had an important impact on heat and mass transfer. Moreover, concentration gradients and sufficient time also contributed to homogeneous welds. For the study of convection in dissimilar laser welding, Yu et al. [12] have obtained the same conclusions as $\mathrm{Hu}$ et al. [11], and they noted that a thickness of intermetallic reaction layer could be decreased if the heat input was reduced to a reasonable range. Esfahani et al. [13] have conducted a dynamic analysis of the flow field based on a turbulence model in the weld pool. Their research also confirmed that the mixing of dissimilar metal materials was the result of convection in the molten pool, and the increase of convective intensity was caused due to the increase of heat. Tomashchuk et al. [14] proposed a simulation model for electron beam dissimilar welding via interlayers based on COMSOL soft, and the influence of the change of welding parameters on the thickness of the diffusion layer was studied.

In summary, several researchers have conducted further theoretical studies of the coupling behaviors of keyhole and molten pool in similar metal laser welding [1-10]; according to simulation methods. However, the numerical analysis of laser welding of dissimilar metal is mainly focused on the study of temperature and heat flow field [10-16]. Although several researchers have investigated the influence of the thickness of the intermetallic reaction layer between two metals on the mechanical properties of the workpiece, studies that have examined the behavior of the keyhole in laser welding of dissimilar materials were rarely reported. Additionally, numerical simulations regarding the laser welding of dissimilar materials have yet to be developed to simultaneously consider the coupling of keyhole formation, heat transfer, and mass transfer. The keyhole formation is an important feature of laser welding, and its dynamic behavior has an important influence on the welding quality.

In this study, a 3D multiphysics transient model considering both keyhole behavior and mass transfer is proposed and is verified by welding experiments. The simulation considers major physical factors such as evaporation, recoil pressure, surface tension, and Rayleigh scattering of the laser beam. Convection, diffusion and keyhole formation are considered simultaneously in the mass transport process between the two metals. The spatter formation mechanism, keyhole and molten pool dynamics, and influence of process parameters on the thickness of the intermetallic reaction layer are analyzed.

\section{Experimental Procedure}

To validate the result of numerical model, 304L stainless steel and pure titanium TA2 with dimensions of $60 \mathrm{~mm} \times 40 \mathrm{~mm} \times 0.8 \mathrm{~mm}$ were used in laser overlap welding experiments, and the 
chemical compositions of the materials are shown in Table 1. In this experiment, 304L stainless steel is placed on top, as shown in Figure 1, since titanium can very easily absorb oxygen and hydrogen in air at high temperature, which makes the weld joint brittle; and crack easily. Moreover, there is little difference in melting point between pure titanium and stainless steel, which does not affect the formation of the molten pool. A fiber laser (IPG YLS-2000, IPG Photonics Corporation, Oxford, MA, USA, maximum power: $2 \mathrm{KW}$, wavelength: $1.07 \mu \mathrm{m}$ ) is used, and continuous laser welding is performed using a KUKA (KUKA Roboter GmbH, Augsburg, Germany) robot movement. During the laser welding process, the side shielding gas is argon, and velocity of gas flow is $15 \mathrm{~L} / \mathrm{min}$. To analyze the influence of different parameters on the welding quality, the range of laser power is $500 \mathrm{~W}-520 \mathrm{~W}$, and the range of welding speed is $3.2 \mathrm{~m} / \mathrm{min}-3.6 \mathrm{~m} / \mathrm{min}$. Laser welding experimental and simulation parameters are shown in Table 2.

Table 1. Chemical compositions of 304L and TA2 (wt. \%).

\begin{tabular}{cccccccc}
\hline \multicolumn{7}{c}{ 304L } \\
\hline $\mathrm{C}$ & $\mathrm{Si}$ & $\mathrm{Mn}$ & $\mathrm{P}$ & $\mathrm{S}$ & $\mathrm{Ni}$ & $\mathrm{Cr}$ & $\mathrm{Fe}$ \\
$\leq 0.03$ & $\leq 1.00$ & $\leq 2.00$ & $\leq 0.035$ & $\leq 0.03$ & $8.00 \sim 11.0018 .00 \sim 20.0$ balance \\
\hline \multicolumn{7}{c}{ TA2 } \\
\hline $\mathrm{Fe}$ & $\mathrm{C}$ & $\mathrm{N}$ & $\mathrm{H}$ & $\mathrm{O}$ & $\mathrm{Si}$ & $\mathrm{Ti}$ \\
$\leq 0.30$ & $\leq 0.10$ & $\leq 0.05$ & $\leq 0.015$ & $\leq 0.25$ & $\leq 0.015$ & balance \\
\hline
\end{tabular}

Table 2. Welding experiment and simulation parameters.

\begin{tabular}{cccc}
\hline Power $(\mathbf{W})$ & Welding Speed $(\mathrm{m} / \mathbf{m i n})$ & Beam Defocus $(\mathbf{m m})$ & Gas Flux Rate $(\mathrm{L} / \mathbf{m i n})$ \\
\hline 500 & 3.2 & 0 & 15 \\
500 & 3.6 & 0 & 15 \\
520 & 3.6 & 0 & 15 \\
\hline
\end{tabular}

The 304L stainless steel and TA2 were cleaned with acetone and dried before welding to avoid the effect of oil and water on the welding joint. Spatter formation and melted pool behavior were observed using a high-speed camera during the welding process. After welding, metallographic specimens were made. Optical microscope (OM), scanning electron microscope (SEM), and energy dispersive spectrometer (EDS) were used to verify the validity of the model.

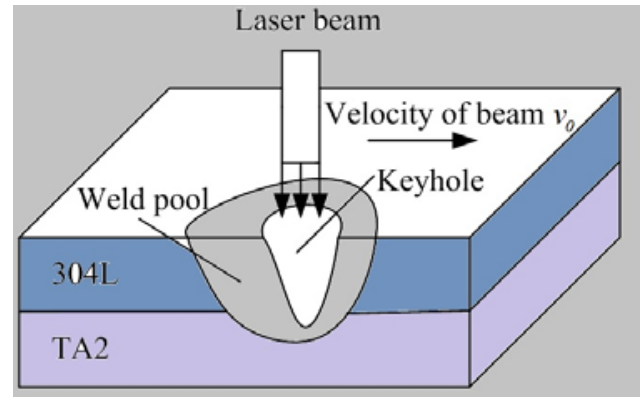

Figure 1. Schematic diagram of laser overlap welding.

\section{Model Description}

The calculated zone of the 3D laser welding model is shown in Figure 1, including the plasma and workpiece zone. Taking into account the physical symmetry in the welding and the calculation speed of computer, half of the welding zone is selected as the calculation domain. Laser welding is 
a complex process of heat and mass transfer, and in order to simplify the calculation, the model is assumed to be as follows:

(1) The effect of side shielding gas on the behavior of keyhole and molten pool is ignored.

(2) The calculated fluid is Newtonian and incompressible and is in local thermal equilibrium; furthermore, this fluid satisfies the basic equations of fluid motion.

(3) The temperature-dependent thermo-physical parameters are calculated, derived from the JMatPro software (Release Version 7.0.0, Sente Software Ltd., Guildford, UK).

(4) In the simulation, only iron and titanium components are considered, and other alloy elements are ignored.

\subsection{Laser Heat Source Model}

In fiber laser welding, the fundamental mode Gaussian beam is the main output mode, in which the spot is circular, and the distribution of light intensity theoretically satisfies the Gauss function, as shown in Equation (1).

$$
q(r)=\frac{3 q_{\max }}{\pi r_{e f f}^{2}} \exp \left(-\frac{3 r^{2}}{r_{e f f}^{2}}\right)
$$

where $q_{\max }$ is the maximum heat flux density of the laser beam, $r$ is the heat source radius, $r_{e f f}$ is the waist radius, and $q(r)$ is the heat flux density at radius $r$.

In the process of laser transmission, the beam has a certain degree of divergence, and the power tends to decrease with an increase in weld depth. In addition, the metal vapor plasma in the keyhole hinders laser energy transmission. At present, the beam quality factor $M^{2}$ proposed by Siegman et al. [17] is generally used to evaluate the quality of the laser beam, as shown in Equation (2).

$$
r(z)=r_{e f f} \sqrt{1+\left(\frac{z-z_{0}}{z_{R}}\right)}
$$

where $z_{0}$ is the longitudinal coordinate of the waist, $z_{R}$ is the Rayleigh constant, and $z$ is the longitudinal coordinate of the heat source.

In laser continuous welding, the radius $r$ in Equation (1) can be expressed as

$$
r=\sqrt{\left(x-v_{0} t\right)^{2}+y^{2}}
$$

where $v_{0}$ is the welding speed, and $t$ is the welding time.

During laser welding, the amount of defocus is set to zero, and the cells in the interface and inside of the keyhole are heated by the beam, while the value of heat flux density is calculated using Equation (1). As mentioned above, the shape of the heat source changes with the shape of keyhole. When the depth of the keyhole increases, the effective radius of the heat source increases. However, the peak energy decreases. It is worth noting that Equation (1) shows the surface heat flux density, not the volume density. It is necessary to transform Equation (1) into the body heat flux according to Zhou et al. [18].

\subsection{Governing Equation}

With the above assumptions, numerical analysis of laser welding of dissimilar metal is carried out by solving equations such as mass, momentum, energy and species transport, as expressed in Equations (4)-(6).

The mass conservation equation is described as

$$
\frac{\partial}{\partial t}(\rho)+\nabla \cdot(\rho \bar{V})+S_{M A}=0
$$

where $\rho$ is density, $\bar{V}$ is velocity vector, and $S_{M A}$ is mass source. 
The momentum conservation equation is described as

$$
\frac{\partial}{\partial t}(\bar{V})+\bar{V} \cdot \nabla \bar{V}=-\frac{1}{\rho} \nabla P+\mu \nabla^{2} \bar{V}+S_{M T}+g
$$

where $p$ is pressure, $g$ is gravity constant, $\mu$ is dynamic viscosity, and $S_{M T}$ is momentum source.

The energy conservation equation is described as

$$
\frac{\partial h}{\partial t}+\bar{V} \cdot \nabla h=k \nabla^{2} T+S_{E}
$$

where $h$ is enthalpy, $k$ is coefficient of thermal conductivity, $T$ is temperature, and $S_{E}$ is energy source.

The mass fraction of each species can be predicted, through the solution of a convection and diffusion equation for the species, as expressed in Equation (7).

$$
\frac{\partial}{\partial \mathrm{t}}\left(\rho Y_{i}\right)+\nabla \cdot\left(\rho \bar{V} Y_{i}\right)=-\nabla \overrightarrow{J_{i}}
$$

where $Y_{i}$ is the mass fraction of species $i$, and $J_{i}$ is the diffusion flux of species $i$. In this study, it is assumed that the molten pool fluid is laminar, implying that $J_{i}$ can be expressed as

$$
\overrightarrow{J_{i}}=-\rho D_{i m} \nabla Y_{i}-D_{T i} \frac{\nabla T}{T}
$$

where $D_{i m}$ is the mass diffusion coefficient for species $i$ in the mixture, and $D_{T i}$ is the thermal diffusion coefficient. According to the above assumptions, the diffusion between titanium and iron is studied, and other alloy elements are not considered.

The mass source term $S_{M A}$ in Equation (4) mainly considers the gas-liquid mass transfer due to the evaporation or solidification of the material. The momentum source $S_{M T}$ in Equation (5) mainly includes the recoil pressure due to the violent evaporation of liquid metal, the momentum loss caused by the solidification of liquid metal, and the Boussinesq buoyancy due to the change of the density of the melted metal. The energy source $S_{E}$ in Equation (6) primarily includes the laser heat source, and the energy loss caused by the radiation and evaporation of the liquid metal on the keyhole wall.

In deep penetration laser welding, the formation of the keyhole is an important feature different from laser conductive welding. On the keyhole free surface, the recoil pressure is the driving force of the keyhole formation. However, surface tension prevents keyhole formation. A general expression for calculating the recoil pressureis as follows [18]:

$$
P_{r}=A B_{0} / \sqrt{T_{w}} \exp \left(-U / T_{w}\right)
$$

where $P_{r}$ is the recoil pressure, $A$ is the adjustment coefficient, which is generally $0.55, B_{0}$ is the evaporation constant, $T_{w}$ is the temperature of the keyhole surface, and $U$ is a constant related to the material.

It is assumed that the recoil pressure $P_{r}$ always vertically acts on the keyhole wall, which is decomposed into axial components during calculation, and the components $P_{x}$ along the $x$-axis is defined as follows:

$$
P_{x}=\frac{n_{x}}{\sqrt{n_{x}^{2}+n_{y}^{2}+n_{z}^{2}}} \cdot P_{r}
$$

where $n_{x}, n_{y}$, and $n_{z}$ are, respectively, the volume fraction gradient components in each axial direction. Using the same calculation method, the other two axial recoil pressures $P_{y}$ and $P_{z}$ can also be calculated. 
During the welding process, the recoil pressure and heat source act on the keyhole surface, meaning that the calculation of the keyhole shape is very important. The keyhole surface is calculated by solving the volume fraction Equation (11) [19], as shown.

$$
\frac{\partial F}{\partial t}+\bar{V} \cdot \nabla F=0
$$

where $F$ is the volume fraction of cells.

During keyhole formation, mass transfer due to evaporation and recondensation is studied, as shown in [20].

$$
\begin{gathered}
S_{l v}=-m_{l v} \\
S_{v l}=m_{l v}
\end{gathered}
$$

where $S_{l v}$ and $S_{v l}$ are the mass source in Equation (4); $m_{l v}$ is cell mass, and a negative value means recondensation.

In simulation, the momentum sink due to solidification is calculated using enthalpy-porosity technique; the latent heat is described using properly changing the specific heat, and the value of momentum sink $S_{m u s h}$ is approximated as follows [21]:

$$
S_{m u s h}=\frac{\left(1-f_{l}\right)^{2}}{f_{l}^{3}+\varphi} A_{m u s h} \cdot \bar{V}
$$

where $f_{l}$ is the liquid volume fraction of cells, $\varphi$ is a tiny number to prevent the denominator from being zero, and $A_{m u s h}$ is a porous medium constant.

Mass transport between dissimilar metals is calculated by solving the mass transport Equation (7); therefore, the mixed phase is composed of iron and titanium in the simulation model. In the mixture, density $\rho$, coefficient of thermal conductivity $k$, specific heat $c_{p}$, and dynamic viscosity $\mu$ are averaged and defined as follows:

$$
\begin{gathered}
\rho=\alpha \rho_{1}+(1-\alpha) \rho_{2} \\
k=\alpha k_{1}+(1-\alpha) k_{2} \\
c_{p}=\alpha c_{p 1}+(1-\alpha) c_{p 2} \\
\mu=\alpha \mu_{1}+(1-\alpha) \mu_{2}
\end{gathered}
$$

where $\alpha$ is the mass fraction of the species, subscript 1 represents the first species, and subscript 2 represents the second species.

\subsection{Boundary Conditions}

As mentioned above, the laser heat source acts on the keyhole surface to heat the workpiece. Meanwhile, energy loss such as gas convection, radiation and evaporation are considered, and the energy balance equation is expressed as

$$
k \frac{\partial T}{\partial n}=q-h_{c}\left(T-T_{\infty}\right)-\sigma \varepsilon\left(T^{4}-T_{\infty}^{4}\right)-W H_{l v}
$$

where $n$ is the vector normal to the liquid-gas interface, $h_{c}$ is the convection heat transfer coefficient, $T_{\infty}$ is the ambient temperature, $\sigma$ is the Boltzmann constant, $\varepsilon$ is the emissivity of radiation, $W$ is the speed of evaporation, and $H_{l v}$ is the latent heat of evaporation.

For other boundaries such as the rear, left, right and bottom of the workpiece, only energy loss due to convection and radiation is considered, and expressed as follows:

$$
k \frac{\partial T}{\partial n}=h_{c}\left(T-T_{\infty}\right)-\sigma \varepsilon\left(T^{4}-T_{\infty}^{4}\right)
$$


For momentum boundary, the surface tension $P_{S}$ is defined as

$$
P_{s}=\kappa \gamma
$$

where $\kappa$ is the surface curvature, and $\gamma$ is the temperature-dependent surface tension coefficient.

\subsection{Numerical Method}

The developed 3D model is solved using a commercial software package named Fluent, and single-machine parallel computing is used in order to improve the calculating speed. The computed domain with dimensions of $6 \mathrm{~mm} \times 2.8 \mathrm{~mm} \times 2.4 \mathrm{~mm}$ is meshed, and the regular hexagon grid is adopted to facilitate the conversion of surface data and volume data in the simulation with a cell size of $0.08 \mathrm{~mm}$. In this model, the mixed phase in species transport model is composed of iron and titanium. Moreover, the phase in multiphase flow model Volume of Fluid (VOF) is composed of plasma and the mixed phase established in the previous step.

The governing equation is discretized using a finite volume method; user-defined functions(UDFs) such as initializing of the calculation domain, source terms, boundary conditions, and material property definitions are written using $\mathrm{C}$ code, and pressure implicit with splitting of operators(PISO) algorithm is used to solve discrete equations. In the PISO algorithm, the pressure correction equation is solved twice; therefore, compared with other algorithms, the PISO algorithm has good convergence and high efficiency.

\section{Results and Discussion}

To improvewelding quality, the formation of excessive intermetallic compounds must be suppressed. Meanwhile, the burning loss of alloying elements in the welding process should be prevented in laser overlap welding. Therefore, precise control of the heat source has a significant impact on joint performance, and the selection of welding parameters is crucial in dissimilar metal welding. In the simulation and experiment, the following welding process parameters, as shown in Table 2, are used to analyze the effects of different parameters on mass transfer between the two metals.

The physical property values used in the calculation are shown in Table 3. Other important parameters used in the simulation are listed in Table 4.

Table 3. Physical properties of 304L and TA2 [1,22].

\begin{tabular}{ccc}
\hline Physical Properties & 304L & TA2 \\
\hline Density $\left(\mathrm{kg} / \mathrm{m}^{3}\right)$ & 7000 & 4110 \\
Specific heat $(\mathrm{J} /(\mathrm{kg} \cdot \mathrm{K}))$ & 712 & 594 \\
Heat conductivity $(\mathrm{W} /(\mathrm{m} \cdot \mathrm{K}))$ & 29 & 40 \\
Dynamic viscosity $\left(\mathrm{N} \cdot \mathrm{s} / \mathrm{m}^{2}\right)$ & 0.007 & 0.005 \\
Boiling point $(\mathrm{K})$ & 3100 & 3315 \\
Surface tension $(\mathrm{N} / \mathrm{m})$ & 1.4 & 1.65 \\
Surface tension temperature coefficient $(\mathrm{N}(\mathrm{m} \cdot \mathrm{K}))$ & $-4.9 \times 10^{-4}$ & $-2.6 \times 10^{-4}$ \\
Coefficient of thermal expansion $(/ \mathrm{K})$ & $1.96 \times 10^{-5}$ & $1.1 \times 10^{-5}$ \\
Melting latent $(\mathrm{J} / \mathrm{kg})$ & $2.47 \times 10^{5}$ & $3.89 \times 10^{5}$ \\
Evaporation latent $(\mathrm{J} / \mathrm{kg})$ & $6.34 \times 10^{6}$ & $8.88 \times 10^{6}$ \\
\hline
\end{tabular}


Table 4. Data used in the simulation.

\begin{tabular}{cc}
\hline Nomenclature & Value \\
\hline Laser beam radius at focus $(\mathrm{mm})$ & 0.2 \\
Planck constant $(\mathrm{J} \cdot \mathrm{s})$ & $5.67 \times 10^{-8}$ \\
Stefan-Boltzmann constant $\left(\mathrm{W} /\left(\mathrm{m}^{2} \cdot \mathrm{K}^{4}\right)\right)$ & $1.38 \times 10^{-23}$ \\
Ambient temperature $(\mathrm{K})$ & 300 \\
Density of plasma $\left(\mathrm{kg} / \mathrm{m}^{3}\right)$ & 0.06 \\
Specific heat of plasma $(\mathrm{J} /(\mathrm{kg} \cdot \mathrm{K}))$ & 610 \\
Heat conductivity of plasma $(\mathrm{W} /(\mathrm{m} \cdot \mathrm{K}))$ & 3.72 \\
Convective heat transfer coefficient $\left(\mathrm{W} /\left(\mathrm{m}^{2} \cdot \mathrm{K}\right)\right)$ & 60 \\
Radiation Emissivity & 0.4 \\
Gas constant $(\mathrm{J} /(\mathrm{kg} \cdot \mathrm{mol}))$ & $8.3 \times 10^{3}$ \\
\hline
\end{tabular}

\subsection{Keyhole Formation and Weld Pool Dynamics}

Figure 2 shows the calculated temperature distribution, keyhole formation and velocity fields in the laser welding of dissimilar materials. At the very beginning of laser welding, when the welding time is less than $3.05 \mathrm{~ms}$, the top surface of 304L stainless steel is heated and metal is melted. When the temperature of the melted metal is higher than the boiling point of the material, violent vaporization occurs. Meanwhile, the metal vapor plasma is formed under the action of the laser. As shown in Figure 2, the keyhole is formed under the action of the recoil pressure due to evaporation, surface tension, and hydrostatic pressure. The recoil pressure causes the keyhole to deepen downwards, while the surface tension prevents the keyhole from moving downwards. As shown in Figure 2c,d, the dynamic and energy balance are achieved on the keyhole wall, and the maximum depth of the keyhole is obtained. These phenomena are consistent with previous research results in similar metal welding, such as Na et al. [3,4], Pang et al. [5-7], Zhao et al. [20] and Tan et al. [21]. Moreover, it can also be seen from Figure 2c,d, as a result of the recoil pressure, that the keyhole also appears in the lower region. Therefore, the lower metal may be squeezed into the upper region. Thus, it is possible that elements are mixed, and intermetallic compounds are formed. However, the mixing of elements and the formation of intermetallic compounds have a significant influence on welding quality [11]. Therefore, keyhole behavior directly affects joint performance in dissimilar metal welding. Moreover, laser heat is transmitted through the keyhole wall to melt the welded metal such that the keyhole shape also affects heat transfer.

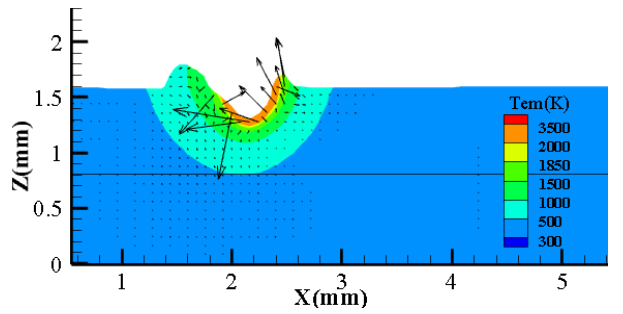

(a)

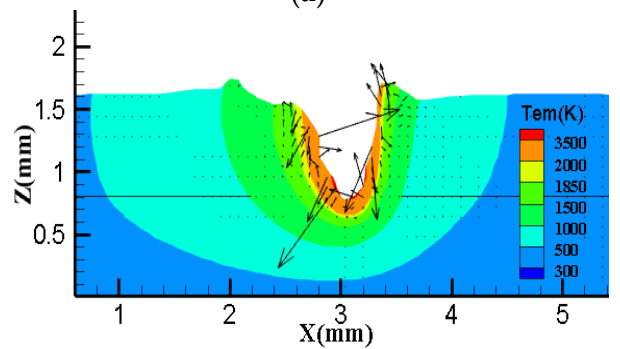

(c)

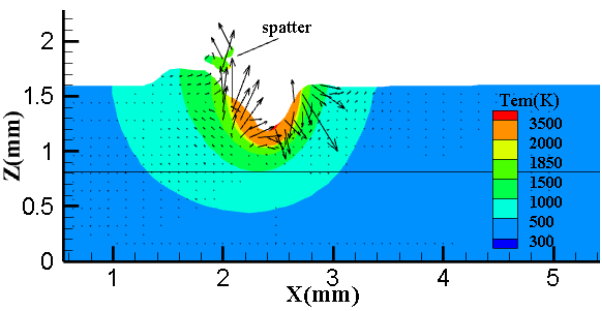

(b)

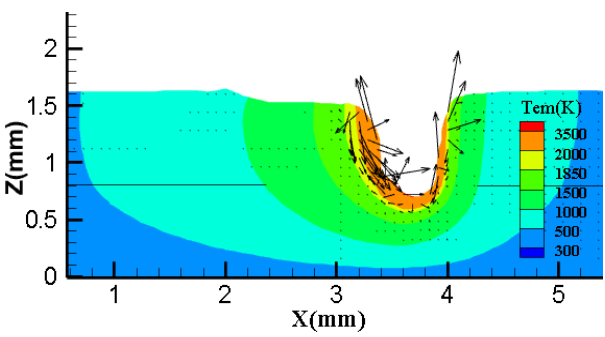

(d)

Figure 2. Longitudinal section views of the calculated temperature and velocity fields in laser welding (laser power $500 \mathrm{~W}$, welding velocity $3.6 \mathrm{~m} / \mathrm{min}$ ): (a) $\mathrm{t}=3.05 \mathrm{~ms}$; (b) $\mathrm{t}=7.20 \mathrm{~ms}$; (c) $\mathrm{t}=18.20 \mathrm{~ms}$; (d) $\mathrm{t}=28.35 \mathrm{~ms}$. 
It can be seen in Figure $2 b$ that spatter is formed in the welding process, which may damage the laser equipment due to spatter into the light path and may also affect the welding quality. In essence, laser welding is the process of rapid heating and rapid cooling of the material, so that the weld pool width is relatively small. Due to the role of recoil pressure, the molten pool near the keyhole wall has an upward trend, as shown in Figure 2b. According to the previous study by Hua et al. [8,9], when the stagnation pressure of the melted metal is higher than the surface pressure, spatter may appear. The shear force and recoil pressure are the driving force of spatter formation, which has been experimentally confirmed (Figure 3).

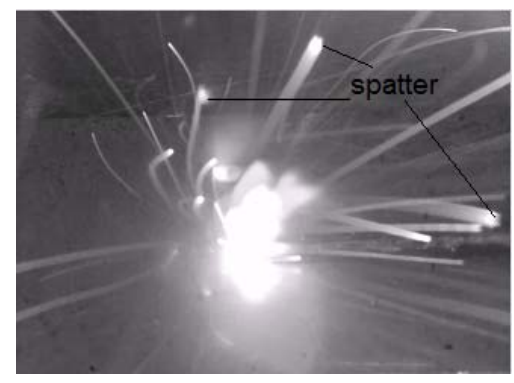

Figure 3. High-speed photographs of spatter formation during laser welding.

The velocity vector indicates the flow state of melted metal in the welding pool, which is an important factor affecting heat and mass transfer. On the surface of 304L stainless steel, the melted metal flows outwards from the keyhole center due to the Marangoni force, as shown in Figure 4a. Meanwhile, the melted metal in the front of the keyhole flows along the keyhole to the rear of the weld pool, which is resolidified to form the weld bead. In the depth direction of the weld bead ( $z$-axis), as shown in Figures 2 and $4 \mathrm{~b}$, the molten pool flow is analyzed from three regions, such as the keyhole wall, near the keyhole, and near the solid phase. The keyhole wall surface is affected by the shear force due to the high-speed movement of the metal vapor plasma, the recoil pressure, and the surface tension, thereby increasing its complexity. Similar to surface tension, the shear force is the tangential force at the gas-liquid interface, the size of which is determined by the velocity of metal vapor plasma inside the keyhole [8,9]. The direction of the recoil pressure is the normal direction of the gas-liquid interface, the size of which is a function of the gas-liquid interface temperature, as shown in Equation (9). The melted metal near the keyhole flows downwards from the top, and the melted metal near the solid phase flows upwards from the welding pool bottom. The simulation results are consistent with previous theoretical calculations by Na et al. [3,4], Pang et al. [5-7] and Zhao et al. [20] and agree with experimental results by Katayama et al. [23]. Moreover, it can be clearly seen from Figures 2 and 5 that the molten pool flow affects the heat transfer and also has an important influence on the mixing of the elements in the weld zone and the formation of the metal reaction layer in dissimilar metal welding, which is a key factor affecting joint performance.

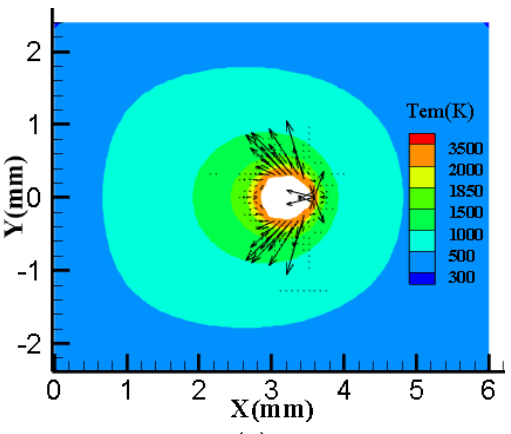

(a)

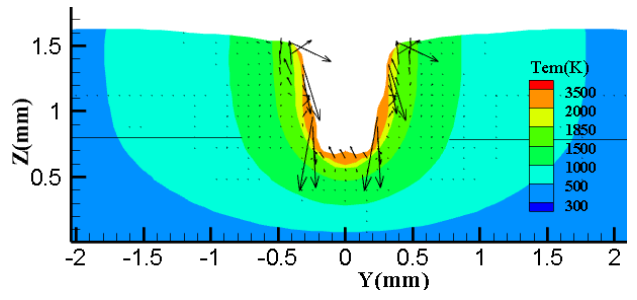

(b)

Figure 4. Calculated temperature and velocity fields in laser welding at time $t=28.35 \mathrm{~ms}$ (laser power $500 \mathrm{~W}$, welding velocity $3.6 \mathrm{~m} / \mathrm{min}$ ): (a) top view; (b) cross-section view. 


\subsection{Mass Transfer}

Fluid flow and diffusion are two basic methods of mass transport, which have been considered by solving Equation (7). Furthermore, keyhole formation is also an important factor affecting melted metal transport, as shown in Figures 5-7, and it cannot be ignored. In this study, the effects of fluid flow, diffusion and keyhole formation on the formation of intermetallic reactive layers are considered simultaneously, and the concentration distribution of elementsis studied in the weld. Using the process parameters in Table 2, simulation and welding experiments are performed to analyze the effects of flow, diffusion and keyhole formation on the formation of intermetallic reaction layers and the concentration distribution of elements. Meanwhile, the change of parameters is also considered, such as laser power and welding velocity.

Figure $5 \mathrm{a}, \mathrm{b}$ shows the effects of different welding speeds on mass transport in dissimilar metal welding with a laser power of 500 W. Compared with Figure 5b, it can be seen from Figure 5a that the keyhole depth and the thickness of the intermetallic reaction layer increase slightly at $x=3.6 \mathrm{~mm}$, and the concentration of $\mathrm{Ti}$ in the weld beam is also higher. This is due to the increase in laser line energy caused by a decrease in welding speed. Therefore, the mass transport of dissimilar metals increases, resulting in an increase in the thickness of the intermetallic reaction layer. As stated by $\mathrm{Hu}$ et al. [11] and Yu et al. [12], if the thickness of the intermetallic reaction layer is excessively large, intermetallic compounds may be produced to attenuate joint performance [24-28]. In addition, excessive Ti in the weld beam is also not conducive to welding quality.

The influence mechanism of laser power change on mass transport is similar to that of welding velocity change, as shown in Figure $5 b$,c. When the laser power increases, the welding line energy increases, and therefore the keyhole depth, the thickness of the reaction layer between the metals and the concentration of $\mathrm{Ti}$ in the weld zone will increase slightly, which is the same as the effect of welding speed decrease on mass transport. The effective variation range of power and welding velocity is very small, which means that laser welding is an important approach for dissimilar metal welding because of its precise control of energy.

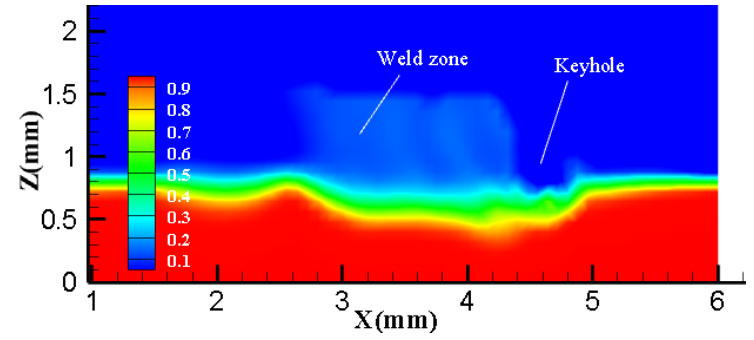

(a)

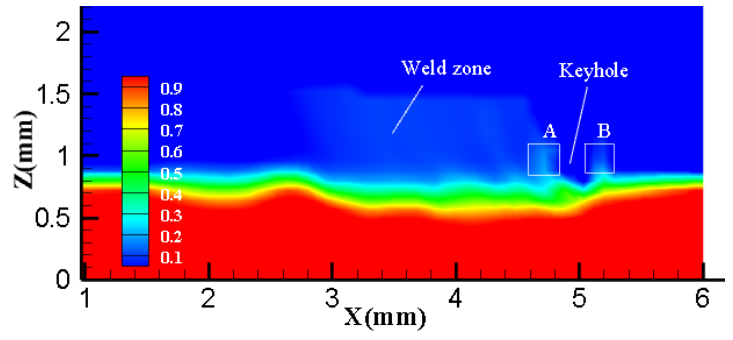

(b)

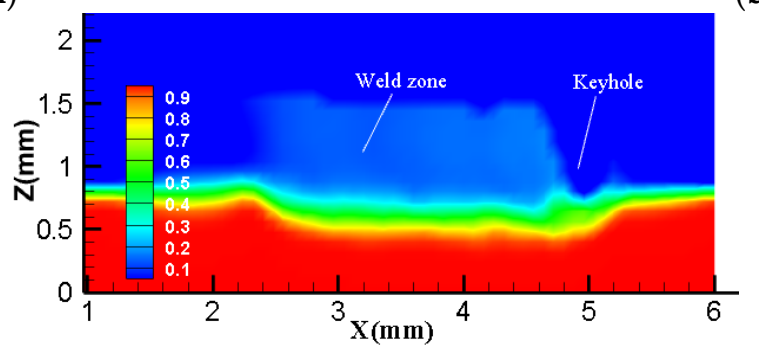

(c)

Figure 5. Longitudinal section views of the calculated concentration profile of Ti for different process parameters: (a) laser power $500 \mathrm{~W}$, and welding velocity $3.2 \mathrm{~m} / \mathrm{min}$; (b) laser power $500 \mathrm{~W}$, and welding velocity $3.6 \mathrm{~m} / \mathrm{min}$; (c) laser power $520 \mathrm{~W}$, and welding velocity $3.6 \mathrm{~m} / \mathrm{min}$. 


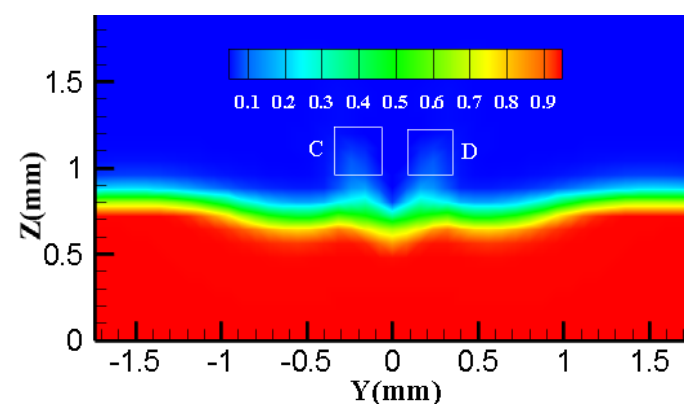

Figure 6. Cross section views of the calculated concentration profile of Ti at time $t=50.15 \mathrm{~ms}$ (laser power $500 \mathrm{~W}$, and welding velocity $3.6 \mathrm{~m} / \mathrm{min}$ ).

In addition to fluid flow and diffusion, keyhole formation has an important influence on the mass transport in dissimilar metal welding. In the welding process, the diameter of the laser beam is very small, and the action time with the metal is extremely short, meaning that the amount of melted metal is very small. When the recoil pressure acts on the keyhole surface in the lower region, the melted metal in the lower region will be pressed into the upper region, as shown in regions A and B in Figure 5b, and regions $\mathrm{C}$ and $\mathrm{D}$ in Figure 6a. Moreover, with an increase in keyhole depth in the lower region, the concentration of Ti increases in the upper weld zone, as shown in Figure 5a,c. Furthermore, during the actual welding process, when the welding conditions change suddenly, or the welding process is unstable, the melted metal from the lower region in the upper region may be re-solidified, and form weld defects, which have been confirmed in welding experiments by Yu et al. [11] and Yang et al. [24].

\subsection{Validation of Simulation Results}

Figure 7 shows SEM image of the welding joint of 304L stainless steel and pure titanium TA2, with a laser power of $500 \mathrm{~W}$ and the welding speed of $3.6 \mathrm{~m} / \mathrm{min}$. The concentration distribution of elements in different positions of welded joints was obtained through EDS to verify the validity of the calculation results.

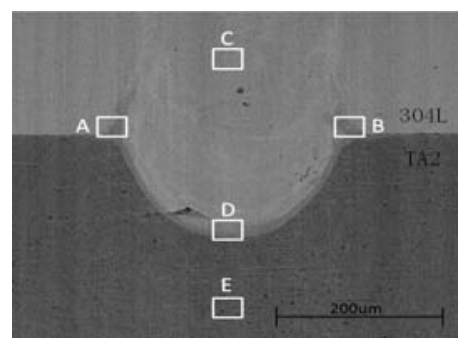

Figure 7. Scanning electron microscope (SEM) image of the welding joint of 304L stainless steel and TA2.

The experimental element distributions measured through EDS are shown in Figures 8-10 and Table 5. As can be seen from Figures 8 and 9 and Table 5, the titanium (Ti) concentration in the weld zone is about 11.23 at. \% (region C), while increasing rapidly to 40.71 at. \% (region D) at the interface regions between $304 \mathrm{~L}$ stainless steel and pure titanium TA2, and finally reaches 100 at. \% (region E) in the lower metal region (pure titanium). This is because the melted Ti enters the molten pool zone through the convection and diffusion occurring in the welding process. As shown in Figures 8 and 9 and Table 5, the Fe concentration in region E is 0 at. \%, while the Ti concentration in region $\mathrm{C}$ is 11.23 at. \%. This indicates that the convection and diffusion of the molten pool has an important influence on mass transport. Moreover, as can be seen from Figure 5, the simulated Ti concentration in the weld zone is found to be 11.75 at. \%, which is consistent with the experimental results. Furthermore, 
the thickness of the intermetallic reaction layer has an important effect on the properties of the joint in dissimilar metal welding. As shown in Table 5 and Figure 9, in the interface regions between 304L stainless steel and pure titanium TA2, the Ti (40.71 at. \%), and Fe (37.73 at. \%) concentrations are very large and very close, possibly due to the fact that intermetallic compounds will be generated $[11,24,28]$. At $x=3.6 \mathrm{~mm}$ in Figure 5b, when the Ti concentration is between 50 at. \% and 42 at. \%, the thickness of the intermetallic reaction layer is about $30 \mu \mathrm{m}$, which is consistent with the experimental results. The difference from the experimental data may arise from the influence of alloy elements such as $\mathrm{Cr}$ and $\mathrm{Ni}$ on mass transfer in 304L stainless steel ignored in the simulation. The simulation results have important theoretical significance.

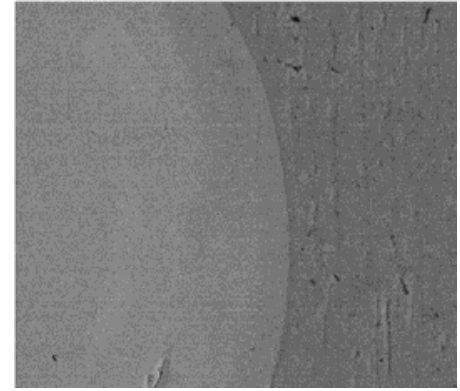

Electron image

(a)

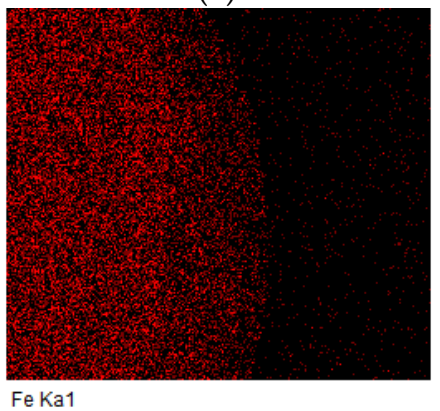

(c)

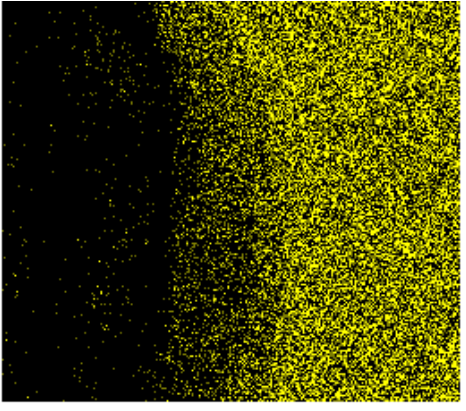

(b)

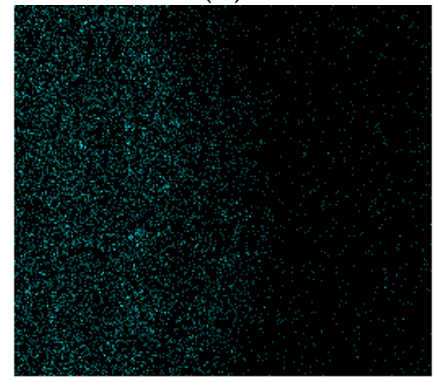

(d)

Figure 8. Distribution of elements near the interface (a) Electron image, (b) Ti, (c) Fe, and (d) Cr.

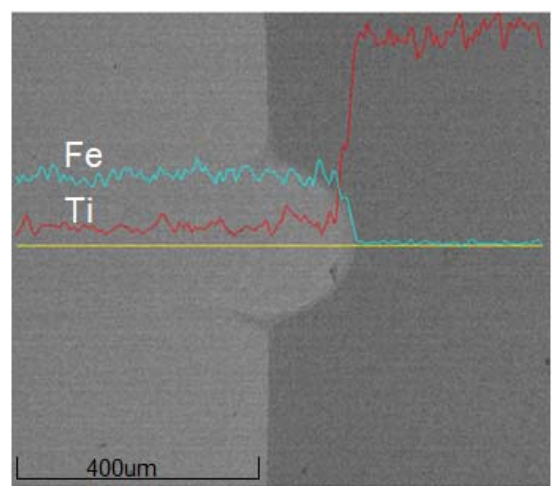

Figure 9. Distribution of elements Ti and Fe along the axis line of weld. 


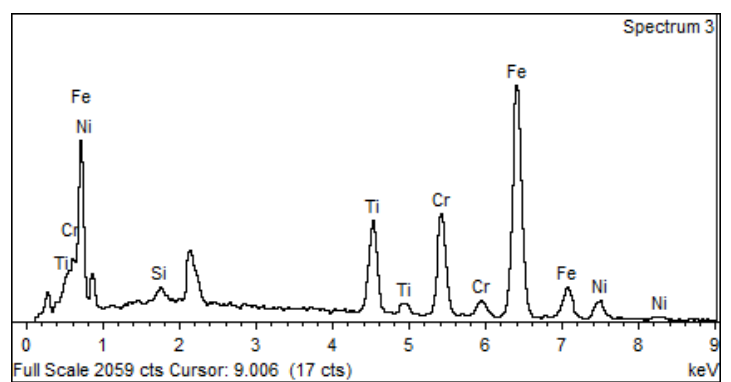

(a)

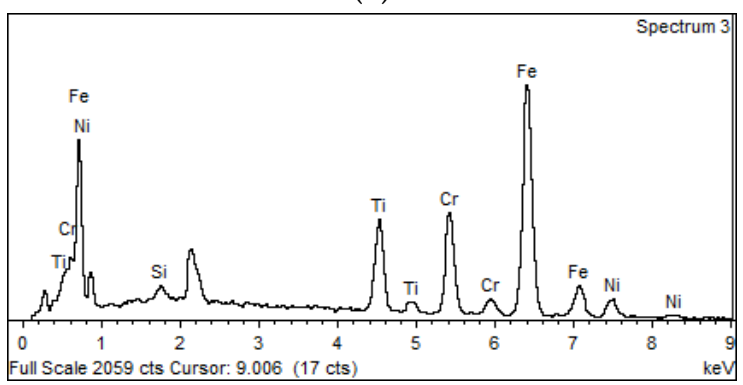

(c)

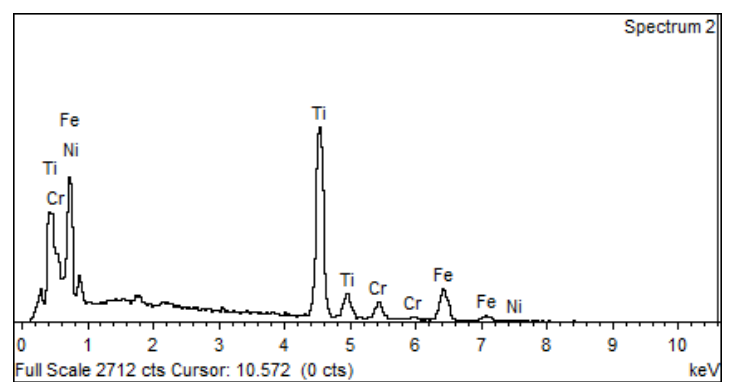

(b)

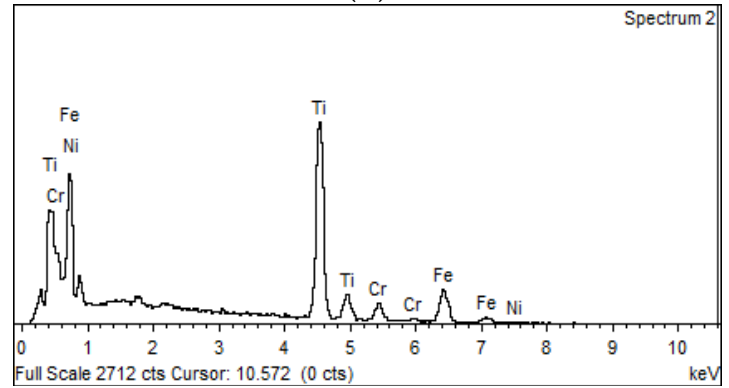

(d)

Figure 10. Energy dispersive spectrometer(EDS) spectra of (a) region A, (b)region $B,(\mathbf{c})$ region $C$, and $(\mathbf{d})$ region $\mathrm{D}$.

Table 5. Experimental atomic fraction of Fe and Ti for various location in Figure 7 (at. \%).

\begin{tabular}{cccccc}
\hline Element & A & B & C & D & E \\
\hline $\mathrm{Fe}$ & 44.45 & 45.39 & 62.50 & 37.73 & 0 \\
$\mathrm{Ti}$ & 33.22 & 41.82 & 11.23 & 40.71 & 100 \\
\hline
\end{tabular}

When the laser keyhole is formed in the lower region, the melted metal in the lower region is squeezed into the upper region due to recoil pressure, as shown in regions A and B in Figure 7 . It can be clearly seen from Table 5 and Figure 10 that the concentration values of Ti in regions A and B are very high, and the concentration of titanium are 33.22 at. \% and 41.82 at. \%, respectively, which verifies the accuracy of the calculated results in Figure 6. The keyhole formation has an important effect on mass transfer in laser welding of dissimilar materials. The calculated results are in good agreement with the experimental results.

\section{Conclusions}

A 3D multiphysics transient model of laser welding of dissimilar materials is proposed, and the dynamic behaviors of the keyhole and molten pool are analyzed. Moreover, mass transport between dissimilar metals is calculated, which is consistent with the experimental results. The primary points of this study are as follows.

(1) Recoil pressure is the driving force for keyhole formation. The laser beam heats the workpiece through the keyhole wall, and the flow of the molten pool has an important effect on energy transmission.

(2) Fluid flow and diffusion are two important mechanisms of mass transport. As the laser line energy increases, the thickness of the intermetallic reaction layer and the diffusion of elements in the weld will increase. Accurate control of laser energy is the key to reduce the formation of intermetallic compounds. 
(3) In the premise of ensuring connection strength and avoiding the burning of alloying elements, the depth of the keyhole in the lower region should be controlled accurately, and the melted metal in the lower region should also be prevented from entering the upper region in large quantities.

Author Contributions: H.Z. and J.W. conceived and designed experiments; Y.F. analyzed the data; B.L. performed the experiments and sampled; J.W. performed the simulation and wrote the paper.

Acknowledgments: This work was supported by the National High Technology Research and Development Program of China (No. 2013AA041003) and the National Natural Science Foundation of China (No. 51665039).

Conflicts of Interest: The authors declare no conflict of interest.

\section{Symbol}

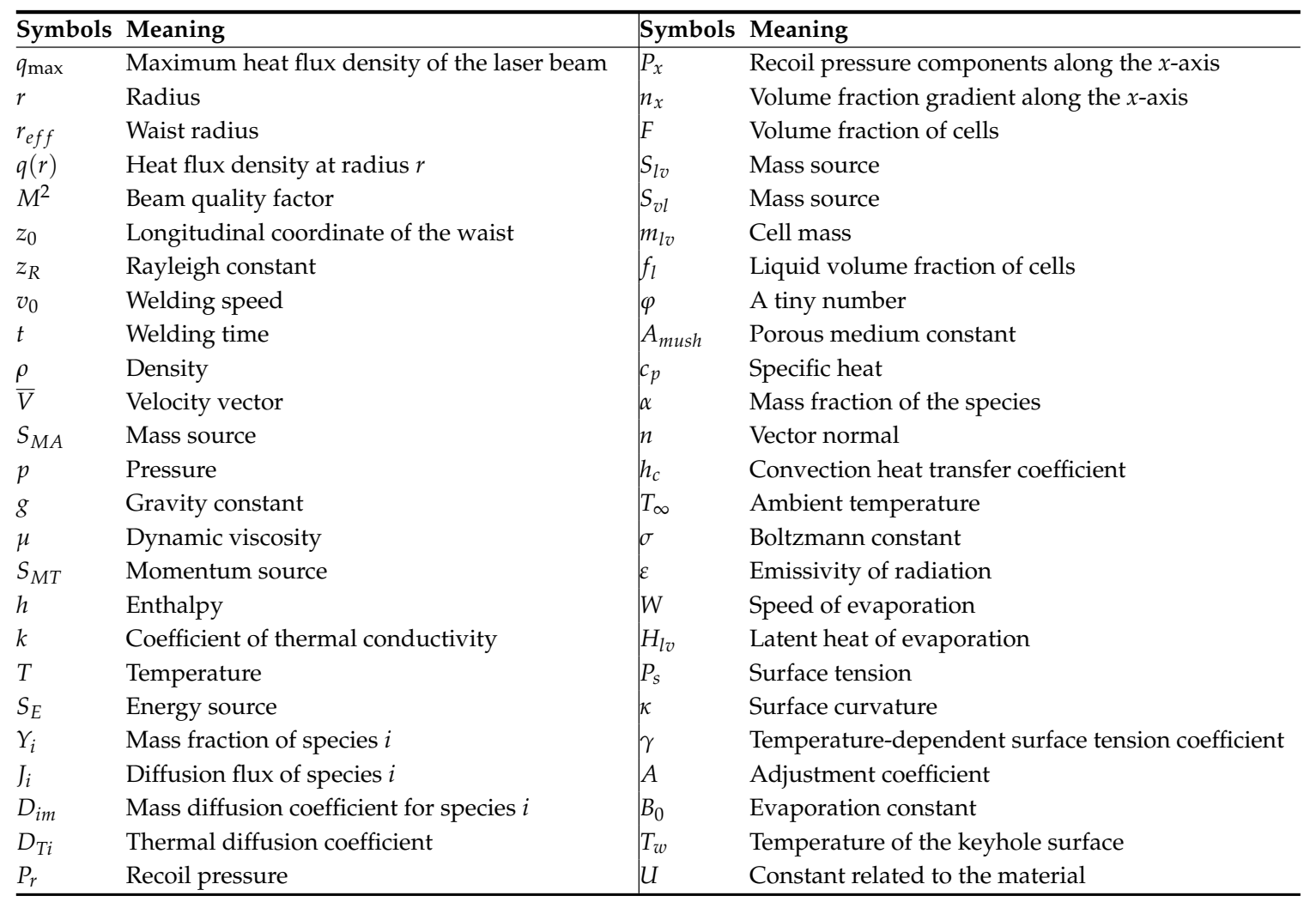

\section{References}

1. Rai, R.; Elmer, J.W.; Palmer, T.A.; DebRoy, T. Heat transfer and fluid flow during keyhole mode laser welding of tantalum, Ti-6AI-4V, 304L stainless and vanadium. J. Phys. D Appl. Phys. 2007, 40, 5753-5766. [CrossRef]

2. Rai, R.; Burgardt, P.; Milewski, J.O.; DebRoy, T. Heat transfer and fluid flow during electron beam welding of 21Cr-6Ni-9Mn steel and Ti-6AI-4V alloy. J. Phys. D Appl. Phys. 2009, 42, 025503. [CrossRef]

3. Cho, W.I.; Na, S.J.; Thomy, C. Numerical simulation of molten pool dynamics in high power disk laser welding. J. Mater. Process. Technol. 2012, 212, 262-275. [CrossRef]

4. Cho, J.H.; Na, S.J. Implementation of real-time multiple reflection and Fresnel absorption of laser beam in keyhole. J. Phys. D Appl. Phys. 2006, 39, 5372-5378. [CrossRef]

5. Pang, S.Y.; Chen, L.L.; Zhou, J.X. A three dimensional sharp interface model for self consistent keyhole and weld pool dynamics in deep penetration laser welding. J. Phys. D Appl. Phys. 2011, 44, 025301. [CrossRef]

6. Pang, S.Y.; Chen, W.D.; Zhou, J.X. Self consistent modeling of keyhole and weld pool dynamics in tandem dual beam laser welding of aluminum alloy. J. Mater. Process. Technol. 2015, 217, 131-143. [CrossRef]

7. Pang, S.Y.; Chen, X.; Zhou, J.X. 3D transient multiphase model for keyhole, vapor plume, and weld pool dynamics in laser welding including the ambient pressure effect. Opt. Lasers Eng. 2015, 74, 47-58. [CrossRef] 
8. Wu, D.Y.; Hua, X.M.; Fang, L. Understanding of spatter formation in fiber laser welding of 5083 aluminum alloy. Int. J. Heat Mass Transfer. 2017, 113, 730-740. [CrossRef]

9. Wu, D.Y.; Hua, X.M.; Huang, L.J. Numerical simulation of spatter formation during fiber laser welding of 5083 aluminum alloy at full penetration condition. Opt. Laser Technol. 2018, 100, 157-164. [CrossRef]

10. Li, S.C.; Chen, G.Y.; Katayama, S.J. Relation between spatter formation and dynamic molten pool during high-power deep-penetration laser welding. Appl. Surf. Sci. 2014, 303, 481-488. [CrossRef]

11. Hu, Y.W.; He, X.L.; Yu, G. Heat and mass transfer in dissimilar welding of stainless and nickel. Appl. Surf. Sci. 2012, 258, 5914-5922. [CrossRef]

12. Zhao, S.S.; Yu, G.; H, X.L. Numerical simulation and experimental investigation of laser overlap welding of Ti6Ai4V and 42CrMo. J. Mater. Process. Technol. 2011, 211, 530-537. [CrossRef]

13. Esfahani, N.M.R.; Coupland, J.; Marimuthu, S. Numerical simulation of alloy composition in dissimilar laser welding. J. Mater. Process. Technol. 2015, 224, 135-142. [CrossRef]

14. Tomashchuk, I.; Sallamand, P.; Jouvard, J.M. Multiphysical modeling of dissimilar welding via interlayer. J. Mater. Process. Technol. 2011, 211, 1796-1803. [CrossRef]

15. Iseav, V.I.; Cherepanov, A.N.; Shapeev, V.P. Numerical study of heat models of laser welding of dissimilar metals with an intermediate insert. Int. J. Heat Mass Transfer. 2016, 99, 711-720. [CrossRef]

16. Tomashchuk, I.; Sallamand, J.M.; Jouvard, J.M. The simulation of morphology of dissimilar copper-steel electron beam welds using level set method. Comput. Mater. Sci. 2010, 48, 827-836. [CrossRef]

17. Siegman, A.E. Defining, measuring, and optimizing laser beam quality. SPIE 1990, 1224, 2-13.

18. Zhou, J.; Tsai, H.L. Investigation of mixing and diffusion processes in hybrid spot laser-MIG keyhole welding. J. Phys. D Appl. Phys. 2009, 42, 095502. [CrossRef]

19. Semak, V.; Matsunawa, A. The role of recoil pressure in energy balance during laser materials processing. J. Phys. D Appl. Phys. 1997, 30, 2541-22252. [CrossRef]

20. Zhao, H.Y.; Niu, W.C.; Zhang, B. Modelling of keyhole dynamics and porosity formation considering the adaptive keyhole shape and three-phase coupling during deep-penetration laser welding. J. Phys. D Appl. Phys. 2011, 44, 485302. [CrossRef]

21. Tan, W.D.; Shin, Y.C. Analysis of multi-phase interaction and its effects on keyhole dynamics with a multi-physics numerical model. J. Phys. D Appl. Phys. 2014, 47, 345501. [CrossRef]

22. Cho, J.H.; Farson, D.F.; Hollis, K.J. Numerical analysis of weld pool oscillation in laser welding. J. Mech. Sci. Technol. 2015, 29, 1715-1722. [CrossRef]

23. Naito, Y.; Katayama, S.; Matsunawa, A. Keyhole behavior and liquid flow in molten pool during laser arc hybrid welding. Proc. SPIE. 2003, 3888, 34-45. [CrossRef]

24. Yang, J.; Li, Y.L.; Zhang, H. Microstructure and mechanical properties of pulsed laser welded $\mathrm{Al} /$ steel dissimilar joint. Trans. Nonferr. Met. Soc. China 2016, 26, 994-1002. [CrossRef]

25. Zhou, K.; Cai, L.L. Online Nugget Diameter Control System for Resistance Spot Welding. Int. J. Adv. Manuf. Technol. 2013, 68, 2571-2588. [CrossRef]

26. Cui, L.; Chen, B.X.; Qian, W. Microstructures and mechanical properties of dissimilar Al/Steel butt joints produced by autogenous laser keyhole welding. Metals 2017, 7, 492. [CrossRef]

27. Xue, Z.Q.; Hu, S.S.; Lee, D.K. Molten pool characterization of laser lap welded copper and aluminum. J. Phys. D Appl. Phys. 2013, 46, 495501. [CrossRef]

28. Kobayashi, S.; Yakou, T. Control of intermetallic compound layers at interface between steel and aluminum by diffusion-treatment. Mater. Sci. Eng. A 2002, 338, 44-53. [CrossRef]

(C) 2018 by the authors. Licensee MDPI, Basel, Switzerland. This article is an open access article distributed under the terms and conditions of the Creative Commons Attribution (CC BY) license (http://creativecommons.org/licenses/by/4.0/). 